EVIDENCE BASED PUBLIC HEALTH POLICY AND PRACTICE

\title{
Compression, expansion, or dynamic equilibrium? The evolution of health expectancy in New Zealand
}

\author{
Patrick Graham, Tony Blakely, Peter Davis, Andrew Sporle, Neil Pearce
}

J Epidemiol Community Health 2004;58:659-666. doi: 10.1136/jech.2003.014910

See end of article for authors' affiliations

\section{Correspondence to:}

Dr P Graham, Department

of Public Health and

General Practice,

Christchurch School of

Medicine and Health

Sciences, PO Box 4345,

Christchurch, New

Zealand; patrick.graham@

chmeds.ac.nz

Accepted for publication

29 December 2003

\begin{abstract}
Study objective: To evaluate the New Zealand evidence for three theories of population health change: compression of morbidity, expansion of morbidity, and dynamic equilibrium.

Design: Using the Sullivan method, repeated cross sectional survey information on functional limitation prevalence was combined with population mortality data and census information on the utilisation of institutional care to produce health expectancy indices for 1981 and 1996.

Setting: The adult population of New Zealand in 1981 and 1996.

Participants: 6891 respondents to the 1981 social indicators survey; 8262 respondents to the 1996 household disability survey.

Main results: As a proportion of overall life expectancy at age 15 the expectation of non-institutionalised mobility limitations increased from $3.5 \%$ to $6 \%$ for men, and from $4.5 \%$ to $8 \%$ for women; the expectation of agility limitation increased from $3 \%$ to $7.5 \%$ for men and from $4.5 \%$ to $8.5 \%$ for women, and the expectation of self care limitations increased from $2.0 \%$ to $4.5 \%$ for men and from 3.0\% to $6.0 \%$ for women. These changes were primarily attributable to increases in the expectation of moderate functional limitation.

Conclusion: The dynamic equilibrium scenario provides the best fit to current New Zealand evidence on changes in population health. Although an aging population is likely to lead to an increase in demand for disability support services, the fiscal impact of this increase may be partially offset by a shiff from major to moderate limitations, with a consequential reduction in the average levels of support required.
\end{abstract}

$\mathrm{T}$ hree broad scenarios have been proposed for the future course of mortality and morbidity in developed countries. Fries, ${ }^{1-3}$ proposed the "compression of morbidity" scenario, which posits an increase in both the absolute expectation and the proportion of the life span free of serious disease and disability. The "relative compression of morbidity" scenario asserts only that the proportion of life free of disease increases. ${ }^{4}$

In contrast with Fries, Gruenberg ${ }^{5}$ and Kramer $^{6}$ suggest that future mortality gains would be achieved largely through improvements in medical care and secondary prevention strategies acting so as to extend the life of people with underlying illness or disability - the so called "expansion of morbidity scenario."

A third theory of population health change was proposed by Manton ${ }^{7}$ who combined elements of both the compression and expansion hypotheses into a scenario he termed "dynamic equilibrium." Manton viewed mortality reductions as, at least partially, the result of reductions in the rate of chronic disease progression. As declines in the rate of disease progression delay the onset of more serious disease states, the dynamic equilibrium scenario implies that mortality reductions will be associated with a redistribution of disease and disability from more to less severe states. Under this scenario the proportion of the life span with serious illness or disability stabilises or decreases, whereas the proportion with moderate disability or less severe illness increases.

These three scenarios entail quite different pressures on health services and systems, and it is therefore important for service planning to determine which scenario is unfolding Health expectancy, an umbrella term for lifetime expectations of particular health states, ${ }^{89}$ is an important tool for monitoring trends in population health, and, in particular, for evaluating the evidence for the compression, expansion, or dynamic equilibrium scenarios. ${ }^{10}$
An overview of health expectancy trends between 1963 and the early 1990s in six low mortality countries supported a dynamic equilibrium model. ${ }^{11}{ }^{12}$ However, recent results from the USA and Australia are not consistent with dynamic equilibrium. US data support a compression of morbidity scenario, particularly at older ages, ${ }^{13}{ }^{14}$ while Australian data suggest an expansion of morbidity scenario, with notable recent increases in the prevalence and expectation of severe handicap. ${ }^{15}$ However, it has been suggested that changes in survey methodology may account for part of these changes. ${ }^{15}$

New Zealand provides an interesting setting for research on population health dynamics, because from the mid-1980s to the mid-1990s, it experienced a period of rapid economic restructuring, resulting in sharp increases in unemployment, widening socioeconomic differentials, and, for many households, declining incomes. ${ }^{16}{ }^{17}$ These changes are all potentially linked to changes in population health. However, previous New Zealand investigations of health expectancy trends have been restricted to a single comparison based on one indicator of functional limitation, the ability to climb stairs, for the period $1980 / 81$ to $1992 / 93 .{ }^{18}$ This study found that the expectation of life free of stair climbing limitations remained unchanged over the study period, despite increases in life expectancy of about two years at age 15 and 1.5 years at age 65. In the absence of more detailed information on the severity of limitations it is impossible to determine whether these data support the dynamic equilibrium or expansion of morbidity scenarios. Consequently, the aim of this study is to provide the first detailed investigation of health expectancy trends for New Zealand and to contribute to the international literature on population health dynamics, in developed low mortality countries.

Abbreviations: SIS, socioeconomic indicators survey; DIS, household disability survey 
Table 1 Comparison of activity limitation questions in the social indicators survey (1981) and the disability survey (1996)

\begin{tabular}{|c|c|c|}
\hline Type of limitation* & Social indicators (SIS)† & Disability (DIS) $\ddagger$ \\
\hline \multirow[t]{2}{*}{ Mobility } & $\begin{array}{l}\text { Can you carry an object of } \\
5 \text { kilos for } 10 \text { metres? }\end{array}$ & $\begin{array}{l}\text { Can you carry something as heavy as a } \\
5 \text { kilo bag of potatoes, while walking, } \\
\text { for } 10 \text { metres-that is, about the length } \\
\text { of } 3 \text { cars parked alongside }\end{array}$ \\
\hline & Can you move between rooms? & $\begin{array}{l}\text { Can you move from one room to } \\
\text { another? }\end{array}$ \\
\hline \multirow[t]{2}{*}{ Agility } & $\begin{array}{l}\text { Can you, when standing, bend down } \\
\text { and pick up a shoe from the floor? }\end{array}$ & $\begin{array}{l}\text { When standing, can you bend down } \\
\text { and pick something up off the floor, for } \\
\text { example, a shoe? }\end{array}$ \\
\hline & $\begin{array}{l}\text { Can you cut your own food? } \\
\text { (such as meat, fruit) } \\
\text { Can you dress and undress? } \\
\text { Can you get in and out of bed? }\end{array}$ & $\begin{array}{l}\text { Can you cut your own food, for } \\
\text { example, meat or fruit? } \\
\text { Can you dress and undress yourself? } \\
\text { Can you get in and out of bed by } \\
\text { yourself? }\end{array}$ \\
\hline
\end{tabular}

*The classification of disability types is that used by Statistics New Zealand in the disability survey. †Possible responses to the SIS questions were: yes with no major difficulty; yes with difficulty; no. ‡Possible responses to the DIS questions were: easily; with difficulty; not at all.

\section{METHODS}

We computed health expectancy estimates for New Zealand women and men in 1981 and 1996 using the Sullivan method, ${ }^{9}$ which combines information on mortality rates with cross sectional information on the prevalence of specific health states, such as non-institutionalised functional limitation or disability, via a life table calculation. The resulting estimates refer to the expectation of life in specific health states for a hypothetical cohort exposed to the specified (1981 or 1996) sets of age specific mortality hazards and health state prevalences. Mathers and Robine demonstrated via a simulation study that the Sullivan method can be used to track changes in health expectancy provided the changes are occurring in a smooth fashion over time. ${ }^{19}$

In this study health expectancies for four health states were of interest: in institutional care; not in institutional care but with specific major functional limitations; not in institutional care but with specific moderate functional limitations; not in institutional care and free of specific functional limitations.

\section{Data sources}

Mortality data

Age-sex specific mortality rates were computed from routine sources by averaging rates for the periods $1980-82$ and 19951997. ${ }^{20}$ The denominator data for these rates were drawn from the population censuses for 1981 and $1996 .{ }^{21} 22$

\section{Institutionalisation data}

Information on the age and sex specific prevalence of institutionalisation was drawn from population censuses conducted in 1981 and 1996 by, by Statistics New Zealand the central statistical office for New Zealand.

\section{Survey data on non-institutional functional limitation prevalence}

The prevalence of non-institutionalised functional limitation was estimated from two sources: the social indicators survey (SIS) conducted in 1981 by the then Department of Statistics $^{23}$ and the household disability survey (DIS) conducted in 1996 by Statistics New Zealand. ${ }^{24}$ Both surveys were complex multi-stage samples of the civilian noninstitutionalised population of New Zealand. Response rates were $80.6 \%$ and $86 \%$, respectively. The SIS was restricted to people aged 15 and over and the achieved sample size was 6891 (2749 men and 4142 women). The DIS included children, however only data from 8262 respondents aged 15 and over were used in the current study (3896 men and 4366 women).

For this study only data from the most comparable functional limitation questions were used. Consequently health expectancy estimates for non-institutionalised functional limitation reported below are restricted to the expectation of the specific functional limitations described in table 1 , which gives the specific question wording used in the two surveys. The mobility limitation and agility limitation classifications are the definitions used by Statistics New Zealand in 1996. Respondents indicating that they were completely unable to perform one or more of the mobility tasks were classified as having "major" mobility limitation. Respondents without major mobility limitation but who reported that one or more of the tasks could be performed only with difficulty were classified as having a moderate mobility limitation. Major and moderate agility limitations were defined similarly.

We also constructed a "self care" limitation indicator based on the mobility and agility items most likely to indicate a need for help with self care activities and to therefore be disabling. Thus people reporting difficulty with moving between rooms, cutting own food, dressing and undressing, or getting in and out of bed were considered to have a self care limitation. Separate analyses for moderate and major self care limitations were not undertaken because major self care limitation was very rare among survey respondents.

The SIS (1981) and DIS (1996) questionnaires differed with respect to the identification of chronic limitations. The preamble to the DIS stated that the questions referred to long term limitations, defined as lasting or likely to last for at least six months and this was repeated later in the questionnaire. In the SIS, long term functional limitation was identified by a separate question concerning "longstanding" injury, illness, or disability. Consequently we report two sets of estimates for 1981. In the first set, all participants indicating complete inability, or difficulty, performing any of the tasks identified in table 1 are counted as having major or moderate functional limitation. For the second set of estimates, participants were counted as having a functional limitation only if, in addition to reporting a specific limitation, they also indicated longstanding illness or disability. Relative to the 1996 definition, estimates for 1981 based on the definition including all reported limitations may overestimate prevalence, whereas, to the extent that respondent interpretations of the term "longstanding" tend to exceed six months, estimates based on the second definition will underestimate prevalence. 


\section{Statistical methods}

We adopted a Bayesian approach to inference implemented via Monte Carlo methods, similar to those developed by Salomon et $\mathrm{al}^{25}$ and used subsequently by the World Health Organisation. ${ }^{26}$ Bayesian analysis models uncertainty via probability distributions and inference is based on "posterior" distributions that, in the current context, are conditional distributions for health expectancy indices, given the observed mortality, institutionalisation, and functional limitation data. In addition to producing standard study summaries such as point estimates and uncertainty intervals, the Bayesian approach permits computation of posterior probabilities of interest such as the probability that health expectancies have increased over time. Posterior probabivlities close to one indicate strong evidence for the effect in question.

Before constructing health expectancy estimates, we modelled the age specific mortality hazards and institutionalisation and functional limitation prevalence as functions of age, via log-linear Poisson (for mortality) and logistic (for institutionalisation and functional limitation) regression models. Age specific predicted values obtained from these models provided the input to the health expectancy calculations. We used flexible quadratic spline models, which can adapt to a wide variety of patterns.$^{27}$ However, in the case of the functional limitation data conventional linear logistic models were used as they performed as well as the spline models in terms of goodness of fit and the plausibility of implied trends. All modelling used uniform prior distributions for model parameters, so that posterior distributions depended only on the model likelihoods. Separate models were fitted for males and females. Further information on technical aspects of the Bayesian modelling and inference procedures can be found in a technical appendix to this paper available from the authors (http://www.chmeds.ac.nz/ pubhealth/pgrahpub).

\section{Sensitivity analyses}

The expectation of health states may change in response to changes in mortality, even in the absence of changes in health state prevalence. For example, in a situation characterised by declining mortality and stable age specific functional limitation prevalence, the absolute expectation of life both with and without limitations will increase. Moreover, the expectation of non-institutionalised health states may change in response to changes in the utilisation of institutional care. For example, in the context of declining utilisation of institutional care, it is probable that some people with limitations who would formerly have been cared for in institutions, now live in the community. As a short hand, this group is henceforth referred to as "de-institutionalised." It is possible that any observed increase in expectation of non-institutionalised limitation could be attributable to greater limitation prevalence among the deinstitutionalised group.

To assess the contribution of changes in mortality and institutional care to observed changes in health expectancy we conducted two sets of sensitivity analyses. In the first analysis only mortality was allowed to change between 1981 and 1996, with functional limitation and institutionalisation prevalences held at 1981 levels. In the second sensitivity analysis both mortality and institutionalisation prevalence were allowed to change. Henceforth the first scenario is referred to as the "mortality change only scenario" and the second as the "mortality decline plus de-institutionalisation scenario." By comparing observed health expectancy estimates for 1996 with the results obtained under the sensitivity analysis scenarios it is possible to ascertain the extent to which observed changes in health expectancy can be attributed to changes in mortality and institutional care utilisation, rather than to changes in age specific functional limitation prevalence.

Construction of the mortality change plus de-institutionalisation scenario required specification of the prevalence of functional limitation among people living in the noninstitutional community in 1996 who would formerly have been in institutional care. Setting this prevalence parameter to 1.0 tests the extreme scenario whereby all de-institutionalised people had functional limitations. ${ }^{28}$ Further rationale and computational details for this sensitivity analysis are given elsewhere ${ }^{28}$ (see also a technical appendix to this paper available from the authors (http://www.chmeds.ac.nz/ pubhealth/pgrahpub.htm).

\section{Ethics}

The study was approved by the Canterbury (NZ) ethics committee. Access to the survey data used in this study was provided by Statistics New Zealand under conditions designed to give effect to the security provisions of the Statistics Act 1975.

\section{RESULTS}

Changes between 1981 and 1996 in life expectancy and functional limitation prevalence

Remaining life expectancy at age 15 increased by 3.4 years, from 56.7 (95\% interval: 56.6 to 56.9 ) years to 60.1 (60.0 to 60.2 ) years for males and by 2.8 years, from 62.6 (62.5 to 62.8 ) to 65.4 (65.3 to 65.5), years for females. Increases of about two years were observed for life expectancy at age 65 . Life expectancy at age 65 increased from 13.3 (13.2 to 13.4) to 15.5 (15.4 to 15.6 ) years for men and from 17.2 (17.1 to 17.3 ) to 19.0 (18.9 to 19.1) years for women.

Table 2 shows the age standardised prevalences of specific functional limitations for the non-institutionalised population in 1981 and 1996. In this and subsequent tables, major and moderate mobility, agility, and self care limitation refer to non-institutionalised limitation. For the 15 to 64 age group the "chronic and acute" and "chronic only" estimates in 1981 are similar. However, for the over 65 age group there are some differences, particularly for female mobility limitation for which the prevalence of moderate limitation was 4.6 percentage points lower under the "chronic only" definition.

Regardless of which definition is adopted for the 1981 estimates, there was little change in the prevalence of major mobility or agility problems between 1981 and 1996. However, there were twofold to threefold increases for moderate functional limitation prevalence in both the 15 to 64 and 65 and over age groups.

Changes in the expectation of life in institutional care The age standardised proportion of the population aged 15 year and older in institutional care declined from $1.2 \%$ to $1.0 \%$ between 1981 and 1996 for males, and from $1.7 \%$ to $1.4 \%$ for women. For ages 65 and over the declines were from $5.4 \%$ to $5.3 \%$ for men and from $8.3 \%$ to $7.5 \%$ for women. However, because of the parallel increase in life expectancy between 1981 and 1996 there was little change in the years of life one could expect to live in an institution: 0.6 to 0.7 years for men at age 15, and 1.4 to 1.6 years for women.

\section{Changes in the expectation of life with specific functional limitations but not in institutional care}

Table 3 (men) and table 4 (women) shows the estimates of health expectancy with specific problems in 1981 and 1996. On all measures, the expectation of limitation was about two times greater for women compared with men in both 1981 and 1996. However, the patterns of change between 1981 and 1996 were similar for men and women. For both men and women there were notable increases in the expectation of 


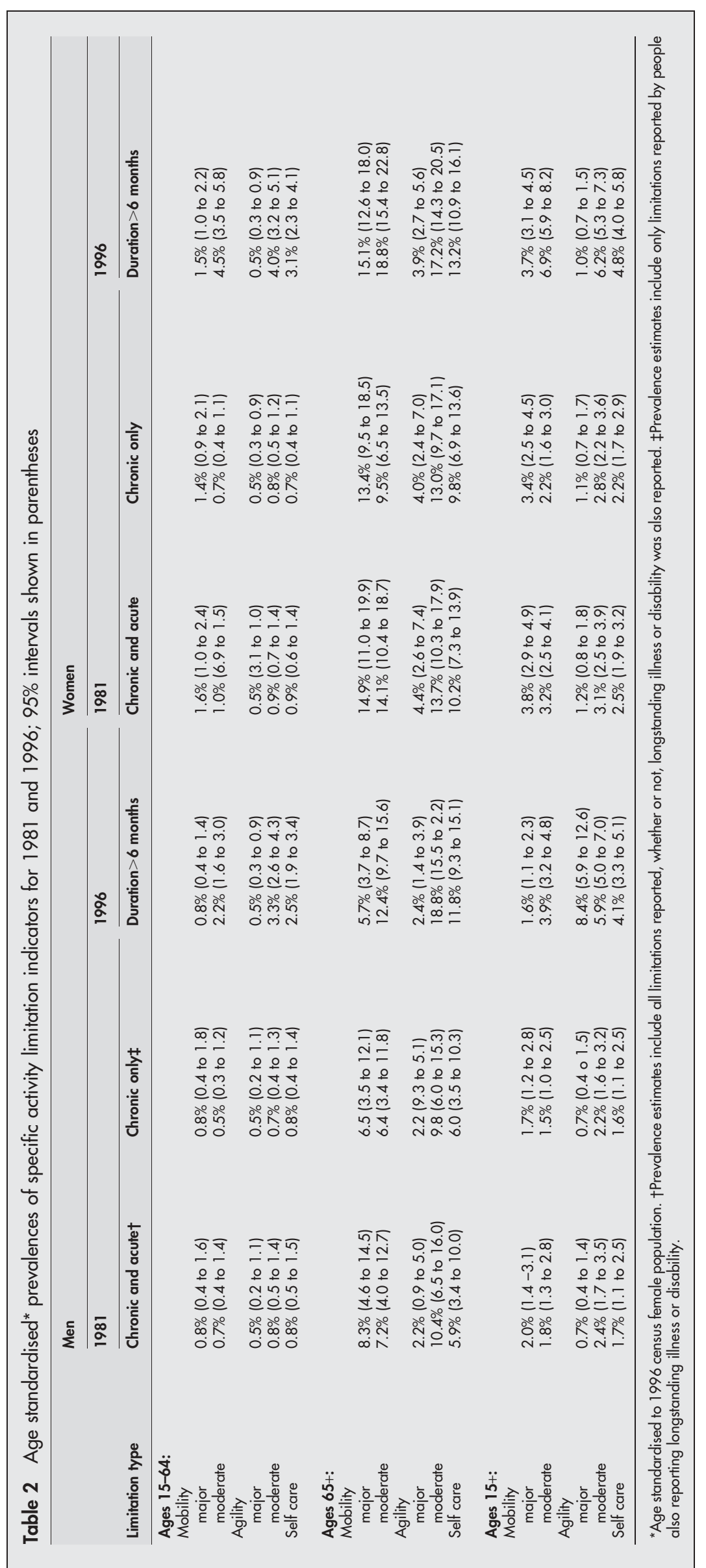



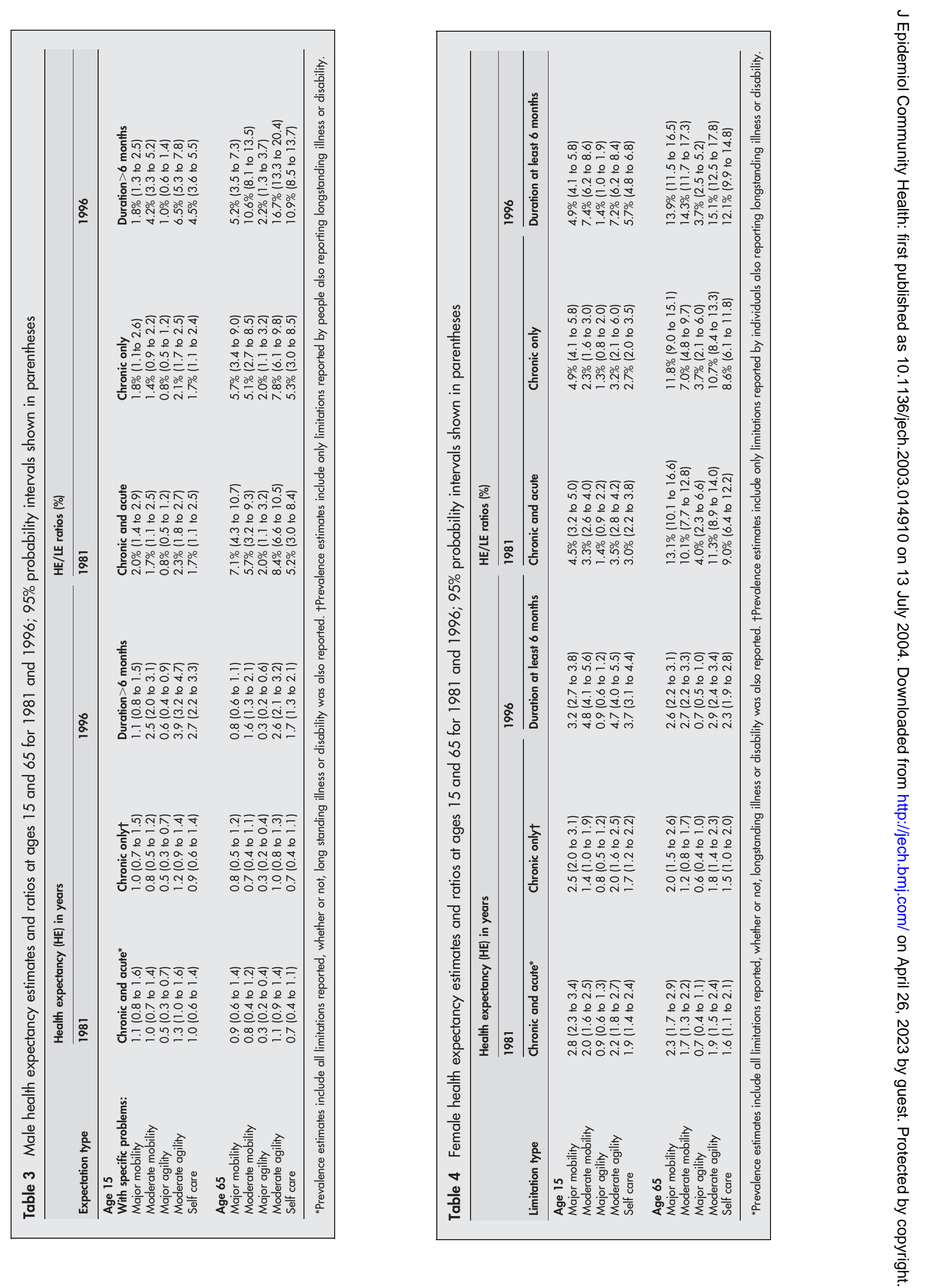
Table 5 Actual 1996 health expectancies compared with projected expectations from 1981 based on two scenarios: (a) mortality decline only since 1981, and (b) mortality decline and an allowance for the effect of de-institutionalisation since $1981-$ men

\begin{tabular}{|c|c|c|c|c|c|c|}
\hline \multirow[b]{2}{*}{ Limitation type } & \multicolumn{2}{|c|}{$\begin{array}{l}\text { Observed (1996) } \\
\text { (that is, as in table 3) }\end{array}$} & \multicolumn{2}{|c|}{$\begin{array}{l}\text { (a) Mortality decline } \\
\text { only since } 1981 \dagger\end{array}$} & \multicolumn{2}{|c|}{$\begin{array}{l}\text { (b) Mortality decline plus de- } \\
\text { institutionalisation }\end{array}$} \\
\hline & $\mathrm{HE}^{*}$ & $95 \%$ interval & HE & $95 \%$ interval & HE & $95 \%$ interval \\
\hline \multicolumn{7}{|l|}{ Age 15} \\
\hline Institutional care & 0.69 & 0.68 to 0.71 & 0.82 & 0.80 to 0.84 & 0.69 & 0.68 to 0.71 \\
\hline Major mobility & 1.08 & 0.78 to 1.48 & 1.31 & 0.99 to 1.71 & 1.31 & 0.98 to 1.71 \\
\hline Moderate mobility & 2.52 & 2.00 to 3.14 & 1.09 & 0.81 to 1.45 & 1.31 & 1.00 to 1.71 \\
\hline Major agility & 0.57 & 0.37 to 0.86 & 0.55 & 0.34 to 0.84 & 0.55 & 0.34 to 0.84 \\
\hline Moderate agility & 3.91 & 3.20 to 4.69 & 1.56 & 1.20 to 1.98 & 1.73 & 1.37 to 2.16 \\
\hline Self care & 2.72 & 2.19 to 3.33 & 2.03 & 1.59 to 2.54 & 2.30 & 1.85 to 2.81 \\
\hline \multicolumn{7}{|l|}{ Age 65} \\
\hline Institutional care & 0.72 & 0.70 to 0.74 & 0.75 & 0.73 to 0.78 & 0.72 & 0.70 to 0.74 \\
\hline Major mobility & 0.80 & 0.55 to 1.13 & 1.04 & 0.73 to 1.43 & 1.04 & 0.73 to 1.44 \\
\hline Moderate mobility & 1.64 & 1.25 to 2.09 & 0.88 & 0.57 to 1.29 & 1.01 & 0.67 to 1.47 \\
\hline Major agility & 0.34 & 0.19 to 0.57 & 0.33 & 0.18 to 0.57 & 0.33 & 0.18 to 0.57 \\
\hline Moderate agility & 2.59 & 2.07 to 3.15 & 1.36 & 0.98 to 1.88 & 1.44 & 1.05 to 1.92 \\
\hline Self care & 1.68 & 1.31 to 2.12 & 0.86 & 0.54 to 1.29 & 0.90 & 0.58 to 1.33 \\
\hline
\end{tabular}

*Estimated health expectancy, reproduced (with 2 decimal places) from third column of table 3: the mean of the posterior distribution for the relevant health expectancy. $† 1981$ Prevalences of functional limitation and institutional care are applied to 1996 mortality data. $\ddagger$ Adjusted 1981 prevalences of functional limitation are applied to 1996 mortality data and institutional care prevalence data. The adjusted prevalences allow for transfer of people with moderate limitation from institutional care to the non-institutional community.

years with moderate mobility and agility problems between 1981 and 1996 and in the ratio of these expectations to total remaining life expectancy (posterior probabilities for the 1996 ratios exceeding 1981 ratios were all at least 0.99). In contrast, there was little evidence of an increase in the expectation of major mobility or agility limitation, with the possible exception of major mobility limitations for women. Regarding the latter, using the "chronic and acute" definition in 1981, the posterior probabilities for an increase in expectation of major mobility limitation were 0.83 and 0.85 for ages 15 and 65, respectively. The estimated increases were 0.4 years at age 15 and 0.3 years at age 65 . Using the more restrictive "chronic only" definition for 1981 the increases were 0.7 years at age 15 and 0.6 years at age 65 , with correspondingly larger posterior probabilities of 0.96 and 0.95 .

\section{The potential impact of declining mortality and utilisation of institutional care}

Tables 5 (men) and 6 (women) report the results of the sensitivity analyses, exploring the potential impact of declining mortality and institutional care utilisation on the results reported above. Considering first the mortality decline only scenario (second block of columns in tables 5 and 6), it is clear that the expectations of moderate limitation predicted under this scenario were substantially less than the actual expectations obtained for 1996. This suggests that only a small fraction of the increase in expectation of moderate limitation reported in tables 3 and 4 can be attributed to declining mortality.

The final block of columns in tables 5 and 6, gives predicted health expectancies under the mortality decline plus deinstitutionalisation scenario. For this scenario it was assumed that the prevalence of moderate limitation among those who would formerly have been in institutional care was one, so as to produce an estimate of the maximum change in expectation of moderate limitations attributable to de-institutionalisation. Comparison with the observed results for 1996, shows that, with the possible exception of the results for women at age 65 , the expectations of moderate limitation in 1996 substantially exceeded those that could have resulted

Table 6 Female 1996 health expectancies compared with projected expectations corresponding to scenarios involving (a) only mortality change since 1981 and (b) mortality change and an allowance for the effect of de-institutionalisation

\begin{tabular}{|c|c|c|c|c|c|c|}
\hline \multirow[b]{2}{*}{ Limitation type } & \multicolumn{2}{|c|}{ Observed (1996) } & \multicolumn{2}{|c|}{ Mortality decline onlyt } & \multicolumn{2}{|c|}{$\begin{array}{l}\text { Mortality decline plus de- } \\
\text { institutionalisation } \ddagger\end{array}$} \\
\hline & $\mathrm{HE}^{*}$ & $95 \%$ interval & HE & $95 \%$ interval & HE & $95 \%$ interval \\
\hline \multicolumn{7}{|l|}{ Age 15} \\
\hline Institutional care & 1.59 & 1.56 to 1.62 & 1.83 & 1.80 to 1.87 & 1.59 & 1.56 to 1.62 \\
\hline Major mobility & 3.21 & 2.70 to 3.79 & 3.03 & 2.59 to 3.52 & 3.02 & 2.59 to 3.49 \\
\hline Moderate mobility & 4.81 & 4.06 to 5.64 & 1.98 & 1.61 to 2.40 & 2.60 & 2.16 to 3.09 \\
\hline Major agility & 0.89 & 0.63 to 1.23 & 0.98 & 0.71 to 1.33 & 0.98 & 0.71 to 1.33 \\
\hline Moderate agility & 4.72 & 4.04 to 5.49 & 2.46 & 2.05 to 2.91 & 2.85 & 2.42 to 3.31 \\
\hline $\begin{array}{l}\text { Self care } \\
\text { Age } 65\end{array}$ & 3.74 & 3.14 to 4.43 & 2.03 & 1.59 to 2.55 & 2.30 & 1.85 to 2.81 \\
\hline Institutional care & 1.71 & 1.68 to 1.74 & 1.88 & 1.85 to 1.92 & 1.71 & 1.68 to 1.74 \\
\hline Major mobility & 2.64 & 2.19 to 3.14 & 2.45 & 2.02 to 2.92 & 2.43 & 2.03 to 2.90 \\
\hline Moderate mobility & 2.72 & 2.22 to 3.29 & 1.68 & 1.32 to 2.09 & 2.25 & 1.81 to 2.75 \\
\hline Major agility & 0.70 & 0.47 to 0.99 & 0.76 & 0.51 to 1.08 & 0.76 & 0.51 to 1.08 \\
\hline Moderate agility & 2.87 & 2.39 to 3.40 & 2.19 & 1.77 to 2.65 & 2.52 & 2.08 to 2.99 \\
\hline Self care & 2.31 & 1.88 to 2.81 & 1.75 & 1.32 to 2.25 & 1.95 & 1.51 to 2.44 \\
\hline
\end{tabular}




\section{Key points}

- Between 1981 and 1996 remaining life expectancy at age 15 increased by 3.4 years for men and by 2.8 years for women; at age 65 increases of about two years were observed for both men and women.

- The expectation of life in institutional care or with noninstitutionalised major functional limitation remained almost constant over the study period.

- The expectation of life with non-institutionalised moderate functional limitation increased substantially over the study period, for both men and women.

- The increase in the expectation of non-institutionalised moderate functional limitations could not be explained by declining utilisation of institutional care.

- The dynamic equilibrium scenario provides the best fit to the New Zealand evidence on changes in population health.

solely from the combined effects of mortality decline and deinstitutionalisation. For both men and women the posterior probability that the observed age 151996 expectations of moderate limitation exceeded those predicted under the mortality decline plus de-institutionalisation scenario was greater than 0.99 . The corresponding posterior probabilities for men at age 65 were at least 0.96

For women at age 65 the equivalent posterior probabilities were somewhat lower: 0.88 for moderate mobility problems, 0.84 for moderate agility problems and 0.77 for self care limitations, and estimated differences were relatively modest. However, given that this scenario was constructed to indicate the maximal impact of the decline in institutional care utilisation by assuming all de-institutionalised people had moderate limitations, it seems unlikely that the observed increases in the expectation of moderate limitation can be explained entirely by such decline.

\section{Health expectancy trends at older changes}

Changes in male health expectancy at older ages paralleled those reported above with little change in major limitations or institutionalisation, but with comparatively substantial changes in the expectation of moderate limitation. For example, as a proportion of total life expectancy the expectation of major mobility limitation at age 85 remained constant at about $3 \%$, whereas the expectation of moderate mobility limitation increased from $17 \%$ to $24 \%$, with $95 \%$ intervals of approximately $\pm 6 \%$. For women the relative expectation of major limitation remained stable and the expectation of moderate mobility limitation increased over the study period (from approximately $10.5 \%$ to $13.4 \% \pm 4 \%$ ). However, in contrast with the results at younger ages the expectation of moderate agility and self care problems at age 85 changed little over the study period.

\section{DISCUSSION}

At ages 15 and 65 we found noticeable increases in the expected number of years lived with non-institutionalised moderate functional limitation between 1981 and 1996, but little change in the expectation duration of non-institutionalised major agility limitation or in institutional care. While there was a suggestion of a slight absolute reduction in the expectation of major mobility limitations for men and a slight increase for women, these changes were small compared with the changes in moderate functional limitation for both men and women.

\section{Policy implications}

The demand for disability support services is likely to increase. However, while the expected duration of support may increase, the average level of support may decrease, because of a shift in the distribution of disability from more to less severe problems.

For men, the large increases in expected years of noninstitutionalised moderate functional limitation could not be accounted for by either longevity increases alone or by the combined effects of longevity increases and declining utilisation of institutional care. However, for older women the declining utilisation of institutional care cannot be completely excluded as a contributor to the observed increases in expectation of non-institutionalised moderate limitation, although it is unlikely that the observed decline in institutionalisation is solely responsible for this increase.

Overall the data suggest that the dynamic equilibrium scenario provides a better fit to the New Zealand data than either the compression or expansion of morbidity scenarios. ${ }^{1-7}$ While these results differ from those reported for Australia ${ }^{15}$ and the US, ${ }^{13}{ }^{14}$ they are consistent with findings for other developed countries for which data are available. ${ }^{11} 1229$ Australian data appear to indicate an expansion of morbidity across all severity levels, ${ }^{15}$ whereas recent results from the US indicate compression of moderate limitations, at least at older ages. $^{13} 14$

While the dynamic equilibrium scenario appears to fit the New Zealand data, an alternative interpretation for the increase in expectation of moderate activity limitation is that the result is artefactual, produced by changes over time in the threshold at which survey respondents report moderate functional limitation. Cross sectional, cross national analyses, using sophisticated new survey and statistical methodology to improve cross population comparability, have reported that inter-population differences in reporting thresholds can have substantial effects on health state prevalence estimates. ${ }^{30}$ While cultural explanations for reductions in reporting thresholds have been proposed, ${ }^{31}{ }^{32}$ these discussions have focused primarily on interpreting historical changes in now developed countries and recent trends in the developing world. Moreover, Riley ${ }^{33}$ argues that as cultural changes could be expected to unfold over at least several decades, the rapidity of some reported changes in morbidity levels ${ }^{34} 35$ suggests that contemporary intra-population change in self reported morbidity prevalence is unlikely to be entirely attributable to cultural changes.

The questionnaire items used in this study entail quite specific tasks and may be less prone to changes in reporting thresholds than more general questions on self rated health. Nevertheless, in the absence of empirical evidence concerning the comparability of thresholds for reporting moderate functional limitation, the possibility that the observed increases in expectation of life with moderate functional limitations can be, at least partially, explained by changes in reporting behaviour remains a possibility. If so, the trends in health expectancy in New Zealand may be more positive than indicated above, although it is an open question whether increased reporting of functional limitations is, of itself, a predictor of increased demand for treatment or support services.

Even if the artefactual explanation of the health expectancy changes for New Zealand reported above is rejected, the implications of the apparent expansion of moderate functional limitation in New Zealand are not necessarily negative. Viewed from the perspective of dynamic equilibrium, an 
expansion of moderate functional limitation is the expected consequence of mortality decline being associated with a redistribution of illness and disability from more to less serious conditions. Consequently, one consequence of the dynamic equilibrium scenario is that the impact of population aging on demand for disability support services may be partially offset by a redistribution of demand from more to less intensive forms of support. Thus while the expected duration of support required may increase, the average level of support required may decrease.

\section{ACKNOWLEDGEMENTS}

We thank Sandra McDonald, Peter O'Brien and Richard Penny of Statistics New Zealand, for facilitating access to the survey datasets.

\section{Authors' affiliations}

P Graham, P Davis, Department of Public Health and General Practice, Christchurch School of Medicine and Health Sciences, New Zealand T Blakely, Department of Public Health, Wellington School of Medicine and Health Sciences, New Zealand

A Sporle, Department of Statistics, University of Auckland, New Zealand N Pearce, Centre for Public Health Research, Massey University, Wellington, New Zealand

Funding: this study was funded by the Health Research Council of New Zealand. The Centre for Public Health Research is supported by a Programme Grant from the Health Research Council of New Zealand.

Conflicts of interest: none declared.

\section{REFERENCES}

1 Fries JF. Aging, natural death and the compression of morbidity. N Engl J Med 1980;303:130-5

2 Fries JF, Green LW, Levine S. Health promotion and the compression of morbidity. Lancet 1989;i:481-3.

3 Fries JF. Measuring and monitoring success in compressing morbidity. Ann Intern Med 2003;139:455-9.

4 Robine JM, Mathers CD. Measuring the compression or expansion of morbidity through changes in health expectancy. In: Robine JM, Mathers CD, Bone MR, et al, eds. Calculation of health expectancies: harmonization, consensus achieved and future perspectives. Paris: INSERM/John Libbey Eurotext, 1993:269-86.

5 Gruenberg EM. The failure of success. Milbank Q 1977;55:3-24.

6 Kramer $M$. The rising pandemic of mental disorders and associated chronic diseases and disabilites. Acta Psychiatr Scand Suppl 1980;62:282-97.

7 Manton KG. Changing concepts of morbidity and mortality in the elderly population. Milbank Q 1982;60:183-244.

8 Sanders BS. Measuring community health levels. Am J Public Health 1964;54:1063-70.

9 Sullivan DF. A single index of mortality and morbidity. HSMHA Health Rep 1971;86:347-54.

10 Robine JM, Jagger C, Mathers CD, et al, eds. Determining health expectancies. Chichester: Wiley, 2003.

11 Robine JM, Romieu I, Cambois E. Health Expectancies and current research. Rev Clin Gerontol 1997;7:73-81.
12 Robine JM, Romieu I, Michel JP. Trends in health expectancies. In: Robine JM, Jagger C, Mathers CD, et al, eds. Determining health expectancies. Chichester: Wiley, 2003:75-101

13 Crimmins E, Saito Y, Ingegneri D. Trends in disability-free life expectancy in the United States, 1970-90. Population Development Review 1997:23:555-572.

14 Freedman VA, Martin LG, Schoeni RF. Recent trends in disability and functioning among older adults in the United States: a systematic review. JAMA 2002;288:3137-46.

15 Davis P, Mathers C, Graham P. Health expectancy in Australia and New Zealand. In: Robine JM, Jagger C, Mathers $C D$, et al, eds. Determining health expectancies. Chichester: Wiley, 2003:391-408.

16 Pearce N. Economic policy and health in the year of the family. N Z Med J 1994; 107:379-81.

17 Kelsey J. The New Zealand experiment: a world model for structural adjustment. Auckland: Auckland University Press, 1995.

18 Davis P, Graham P, Pearce N. Health expectancy in New Zealand, 19811991: social variations and trends in a period of rapid social and economic change. J Epidemiol Community Health 1999;53:519-27.

19 Mathers CD, Robine JM. How good is Sullivan's method for monitoring changes in population health expectancies? J Epidemiol Community Health 1997;51:80-6.

20 National Health Statistics Centre/New Zealand Health Information Service. Mortality and demographic data 1980, 1981, 1982, 1995, 1996, 1997. Wellington, NZ: Department of Health/Ministry of Health, $1983,1984,1996,1997,1998$.

21 Department of Statistics. 1981 Cenus of population and dwellings Wellington, NZ: Department of Statistics, 1983.

22 Statistics New Zealand. 1996 Census of population and dwellings. Wellington, NZ: Statistics New Zealand, 1996.

23 Department of Statistics. Report on the social indicators survey. Wellington, NZ: Department of Statistics, 1984.

24 Statistics New Zealand. Disability counts. Wellington, NZ: Statistics New Zealand, 1996

25 Salomon JA, Mathers CD, Murray CJL, et al. Methods for life expectancy and healthy life expectancy uncertainty analysis. Global programme on evidence for health policy working paper no 10. Geneva: World Health Organisation, 2001.

26 Mathers CD, Murray CJL, Lopez AD, et al. Global patterns of health expectancy in the year 2000. In: Robine JM, Jagger C, Mathers CD, et al, eds. Determining health expectancies. Chichester: Wiley, 2003:336-58.

27 Greenland S. Dose-response and trend analysis in epidemiology: alternatives to categorical analysis. Epidemiology 1995;6:356-65.

28 Graham P. A note on the use of sensitivity analysis to explore the potential impact of declining institutional care utilisation on disability prevalence. Population Health Metrics 2004;2:3. (http://www. pophealthmetrics.com/ content $/ 2 / 1 / 3$ )

29 Robine JM, Mathers C, Brouard N. Trends and differentials in disability-free life expectancy: concepts, methods and findings. In: Caselli G, Lopez A, eds. Health and mortality among elderly populations. Oxford: Clarendon Press, 1996: 182-201.

30 Mathers CD, Murray CJL, Salomon JA, et al. Healthy life expectancy: comparison of OECD countries in 2001. Aust N Z J Public Health 2003;27:5-11.

31 Johansson SR. The health transition: The cultural inflation of morbidity during the decline of mortality. Health Transition Review 1991;1:39-65.

32 Murray CJL, Chen LC. Understanding morbidity change. Population Development Review 1992;18:481-503.

33 Riley JC. From a high mortality regime to a high morbidity regime: Is culture everything in sickness. Health Transition Review 1992;2:71-7.

34 Riley JC. The prevalence of chronic disease during mortality increase: Hungary in the 1980s. Population Studies 1991;45:489-96.

35 Riley JC. The risk of being sick: morbidity trends in four countries. Population Development Review 1990;16:403-32. 